\title{
Would Interactive Textbooks take Dental Education to a New Level of Learning?
}

\section{Hesham F Marei ${ }^{1 *}$ and Gohar Wajid}

${ }^{1}$ Assistant Professor of Oral and Maxillofacial Surgery, Department of Biomedical Dental Sciences, College of Dentistry, University of Dammam, Kingdom of Saudi Arabia ${ }^{2}$ Assistant Professor of Medical Education, University of Dammam, Kingdom of Saudi Arabia

\author{
Abstract \\ Objective: To evaluate the educational need for interactive textbooks designed by IBook Author application, and \\ to assess the feasibility of their implementation as a learning tool.
}

Materials and methods: This study involved the participation of 42 dental students, and 28 faculty members working in one dental college. The study involved training on the creation of interactive textbooks using IBook Author application. A questioner was used to get participants' feedback about the value, educational need, and feasibility of their implementation.

Results: All faculty members agreed that the application would solve some of the existing educational problems, and it will help them in preparing their handouts. All the students agreed that they would be more attracted to learn from an interactive textbook than from printed or non-interactive electronic textbook. The college administration reported that the implementation of interactive textbooks is within its capabilities, and resources.

Conclusion: There is an educational need for interactive textbooks that are designed by IBook Author as they can be regarded as a highly motivating environment for students' learning, and can be easily implemented by the medical teacher in dental education.

Keywords: Interactive textbooks; Computer aided learning; Interactive learning; E-Learning; Computer based learning

\section{Introduction}

IBook Author is a new application that has been announced by Apple on 19/ 01/ 2012. It allows the creation of an interactive multitouch textbook, which involves video, interactive diagrams, 3D objects, text with sound clips, shapes, charts, tables, multi-touch widgets, and animations that burst off the page. With this application, e-textbooks are no longer limited to static pictures to illustrate the text. Now students can dive into an image with interactive captions, rotate a 3D object, and watch a video anywhere in the page, highlight text, take notes and find easily definitions in the glossary [1].

The application also provides a solution for students' selfassessment at different book chapters. It allows readers to test their knowledge using a variety of question types such as multiple choices, choose the correct image, label the image, or a mix of all three with immediate feedback [1].

The literature has a significant number of articles discussing computer-assisted learning (CAL) in different areas of health education [2-5]. Computer assists learner to interact at different levels. The first level is interaction with the content and the learning materials, and the second level is the interaction with content, tutors, and peers through e-learning or virtual environment [3]

Computer based instruction programs as an example of interaction with content were found to raise student examination scores, produce positive changes in student attitudes toward teaching and decrease the amount of time needed for learning instructions [6].

In dental education, CAL was recommended as an adjunct to conventional teaching or a means of self-instruction, as the interactive ways of presenting material elicits positive responses from students and consequently motivates them to learn [7]. Eitner et al. [8] found that interactive, problem-oriented CAL and computer-aided-testing improve the qualitative and quantitative parameters of knowledge transfer and cognitive knowledge assimilation. The same conclusion was drawn in a study comparing the use of interactive digital instruction with a conventional textbook of oral radiographic anatomy, as the students' learning experience was enhanced by enabling them to interact and engage with the course material [9].

In medical education, Harden and Smyth stated that computerbased study guides offer advantages over print-based guides. It can be easily updated, and it allows students to move quickly and easily from one section to another, and easily updated [2].

Although the advances in communication technology and the wide use of the internet have made CAL programs readily available, there are some obstacles that could jeopardize the implementation of effective learning. Some of these obstacles are the complexity of the educational software, which may confuse and discourage the users, inflexible platforms, which do not allow enough teacher control over the instructional methodology and content delivery, lack of IT support teams, and lack of an effective IT infrastructure [10]. A problem that is emerged with the CAL is the need for educational technologists. Educational technologists are "specialists who are responsible for resolving the tensions between what educators want and what is technically possible and desirable" [5]. Another limitation for the use of CAL is the cost of producing educational software, and resistance from students, and faculty to participate in using these programs due to either lack of interest or being incompetent in using such programs $[4,11]$. Cross and Shutt stated that the development of CAL resources

*Corresponding author: Hesham F. Marei, College of Dentistry, University of Dammam PO Box 1982, Dammam 31441, Kingdom of Saudi Arabia, Tel: +966-38574928, +966548027750; Fax: +966-3-8572624; E-mail: hesham.marei@yahoo.com Hesham.marei@me.com

Received January 19, 2013; Accepted April 24, 2013; Published May 05, 2013

Citation: Marei HF, Wajid G (2013) Would Interactive Textbooks take Denta Education to a New Level of Learning? Surgery S11: 002. doi:10.4172/2161-1076. S11-002

Copyright: @ 2013 Marei HF, et al. This is an open-access article distributed under the terms of the Creative Commons Attribution License, which permits unrestricted use, distribution, and reproduction in any medium, provided the original author and source are credited. 
should be accessible at any time, from anywhere, easily updated, and inexpensive [12].

In an attempt to provide a learning tool that allows interaction with its content without facing the above-mentioned problems, I-textbooks designed by IBA application are suggested as an option.

The aim of this study was to evaluate the educational need of interactive textbooks (I-textbooks) designed by IBA application, to assess the perception of dental students, faculty members, and to evaluate the feasibility of their implementation as a learning tool.

\section{Materials and Methods}

The college research committee approved the study, and it has followed the principles in the Declaration of Helsinki.

This study involved the participation of 42 dental students, and 28 faculty members working in one dental college. Three of the twentyeight faculty members were regarded as administrative staff as they are involved in the decision-making process in the College Board. The students were selected randomly, while all faculty members were invited to the presentation. They belonged to different departments and ranged from newly appointed demonstrators to senior professors.

The study involved one-hour presentation on the use of IBA application. The presentation used the materials, which are presented over Apple website [1] to introduce IBA, and I-textbooks to the whole group, then the presentation was followed by an hour of a step by step demonstration on the use of the application in creating an I-textbook. One of the I-textbooks that contain video, interactive diagrams, 3D objects, sound clips, multi-touch widgets, and animations was presented by a faculty member, who is trained on the use of the application (Figures 1 and 2).
All participants were requested to meet after one week. During that week, faculty members expected to practice the use of the IBA application in creating an I-textbook using their hardware or college hardware assigned specifically for that purpose. Students were asked to learn from I-textbook that was designed to cover a topic related to oral surgery. The created I-textbook used all the features of the application (Figure 3). The participants were allowed to visit the tutor to discuss any difficulties that they arose during their practice. In the second meeting, all participants gave their feedback. They discussed their work and commented on the use of IBA, and I-textbook. All the participants were requested to continue using IBA, and I-textbook till the third meeting, which was arranged at the end of the semester. In that meeting, a questionnaire was used to collect participants' feedback.

The author followed the methodology described in similar articles for preparation of the questionnaire $[4,13]$. The author analyzed different parts of the articles to include the questions that were relevant to the study objectives, and then the draft form of the questionnaire was sent to a panel of three experts in the health education to analyze the relevant questions, and to come with the final version. All the questions were simple and direct, and the responses were on a 5-point Likert scales "Poor, Fair, Average, Good, Excellent"

The questionnaire was distributed to all the participants at the end of the third meeting to evaluate the participants' experience on the use of the new application, and the feasibility of implementation of I-textbooks. parts:

The questionnaire contained 19 questions and was divided into 5

$1^{\text {st }}$ part: for faculty \& students on which questions assessed faculty, and students' computer, and IT skills.

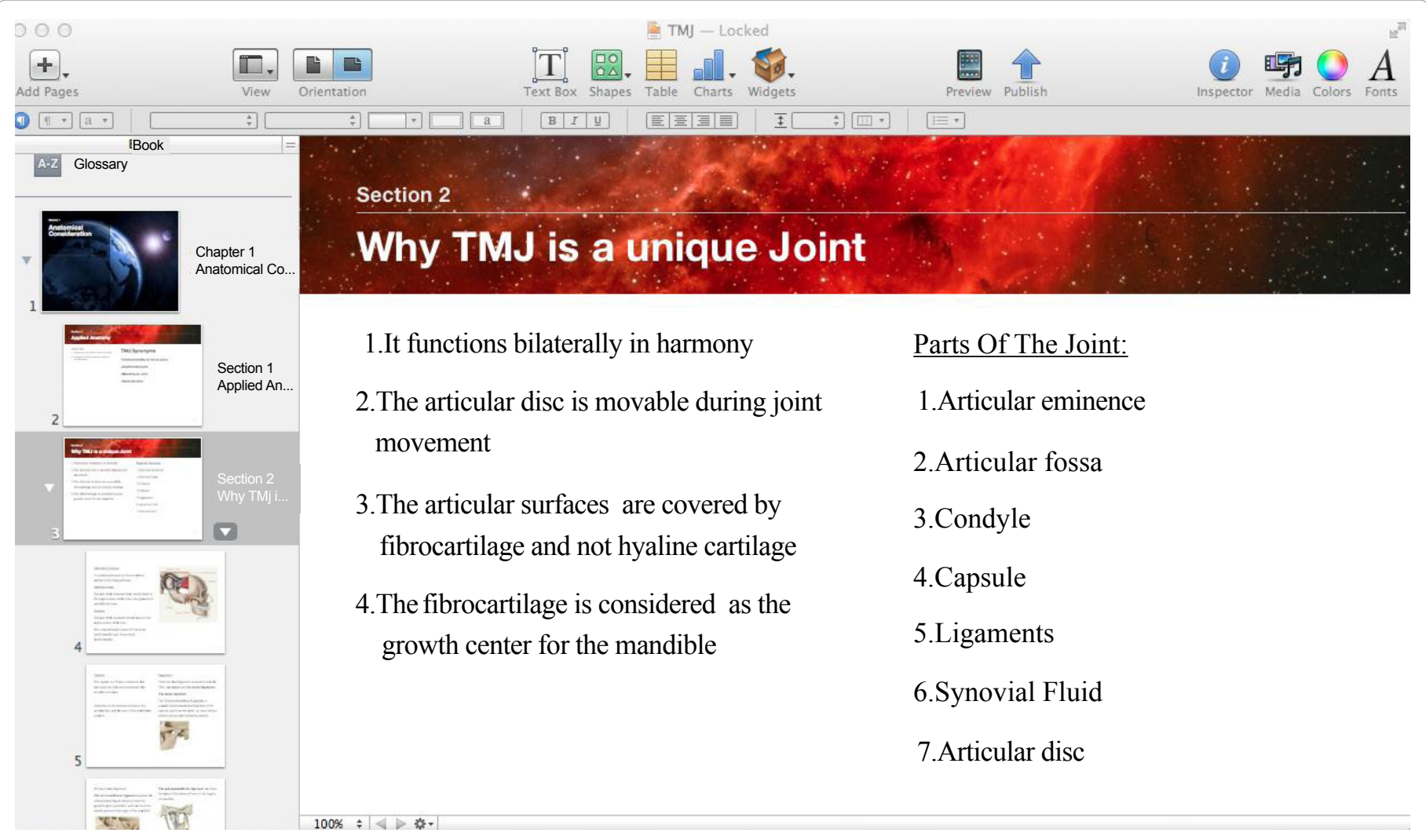

Figure 1: Interactive textbook in the creation form using IBA template. 


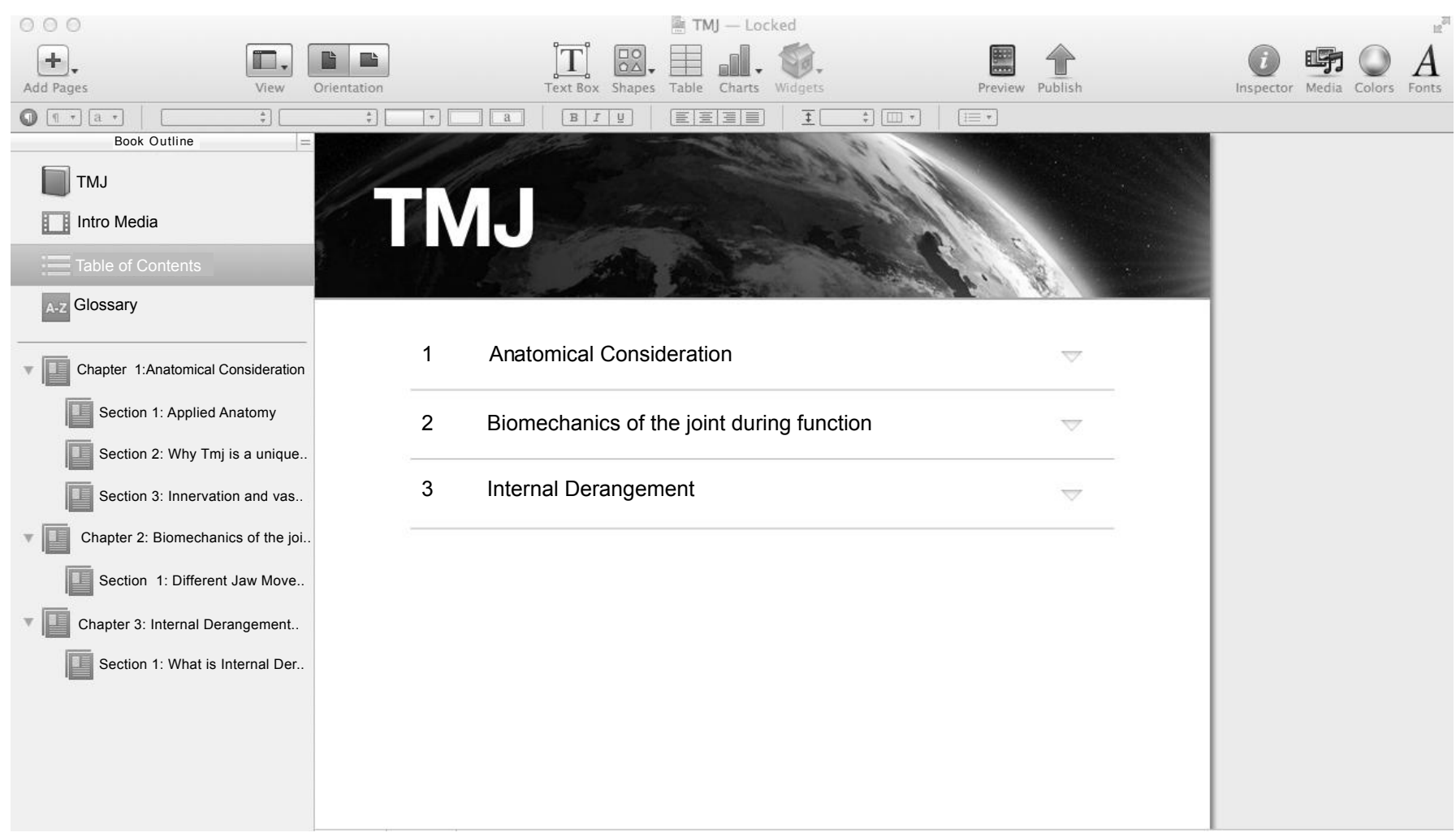

Figure 2: Book outline in the creation form using IBA template.

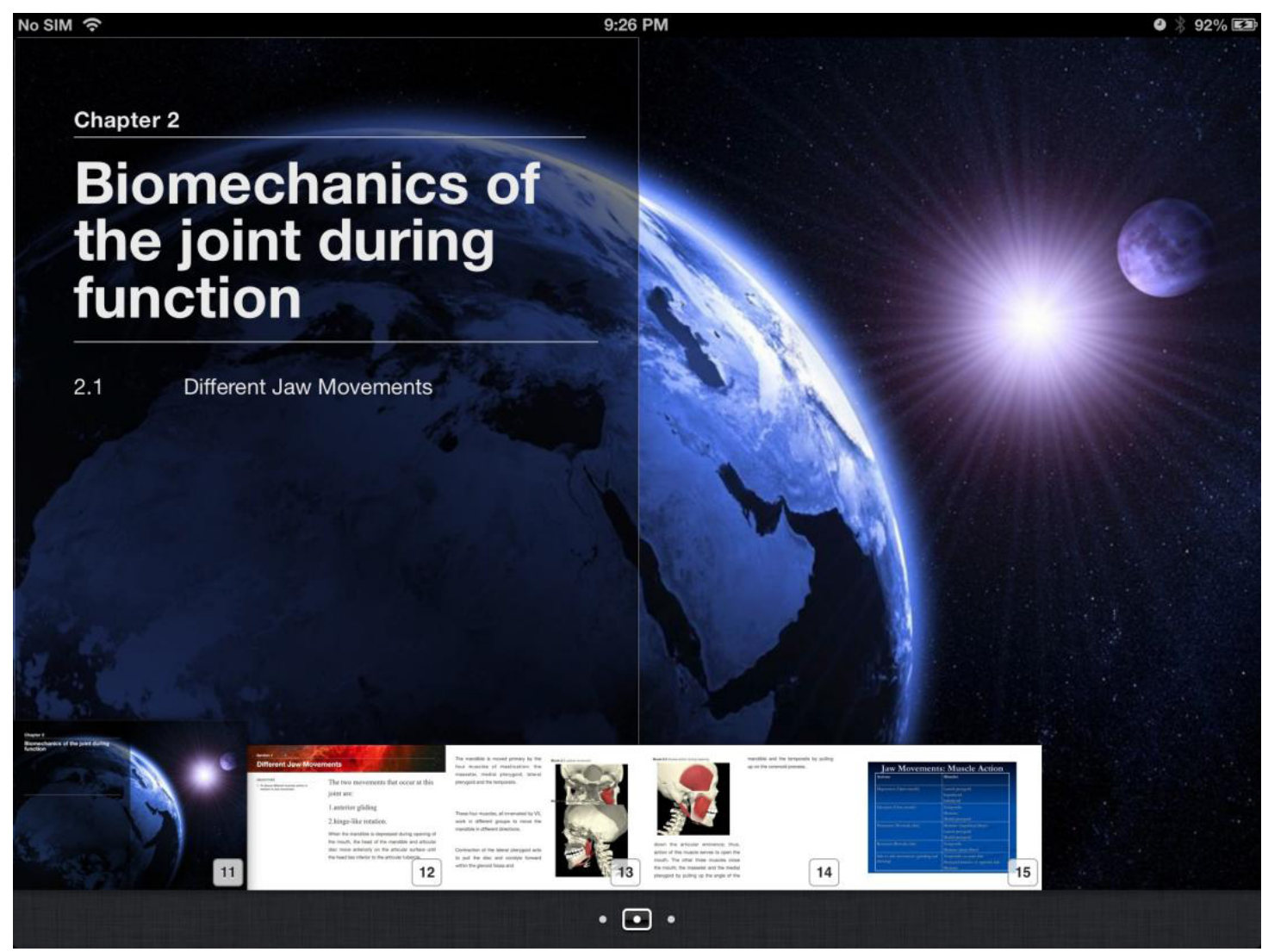

Figure 3: A sample of a book chapter with different sections in the display form on I Pad using iBooks application. 
$2^{\text {nd }}$ part: for faculty \& students on which questions assessed the educational need and value to the stakeholders.

$3^{\text {rd }}$ part: for faculty, and students on which questions assessed the technical feasibility of creating, and using I-textbook.

$4^{\text {th }}$ part: for administration staff on which questions assessed the costs and benefits for implementing I-textbook.

$5^{\text {th }}$ part: for any comments about the new application, and to be filled by faculty, students, and administration staff.

\section{Results}

The results showed that 7 participants out of 70 were aware of the new application before the first presentation, and their knowledge was poor. Thirty-five participants own apple hardware that is compatible with IBA. All participants are sharing information daily using the internet, and have at least the average computer skills that allow them to prepare their presentations either using PowerPoint or Keynote. All faculty members agreed that the application would solve some of the existing educational problems such as preparation of interactive handouts, and study guides. All the students agreed that they were more attracted to learn from I-textbook than printed or non-interactive e-book. Concerning overall satisfaction, all the participants' feedback was between good, and excellent. Half of participants preferred having the printed textbook available in the college library along with the I-textbook. Ten faculty members reported their willingness to shift from their current hardware to Apple hardware that is compatible with IBA. The college administration reported that the implementation of I-textbooks is within its capabilities and resources, and its readiness to prepare an internal library that has the necessary facilities that allow the creation, and the use of I-textbooks.

\section{Discussion}

It is not wise today to prepare future generations with learning tools for a world that is already past. Textbooks have been limited to static text, pictures, graphs, tables, and charts for many years. They belonged to a world that did not have such advances in technology, or that much daily update in knowledge. Printed textbooks were for a world, where sharing of knowledge via social networking services like Face book, Twitter, iTunes did not exist.

Many educational methodologies are retained based on tradition, and new methods are adopted based on fashion. Any educational practice should be based on educational research, which focuses on improving quality and considering resource utilization [14]. Computers are sometimes seen as an answer to the problems of maintaining quality in education when student numbers are increasing, but resources are decreasing [2].

Since a large number of published articles are in favour of interactive learning either purely with content or content, tutors, and peers, it has become crucial to learn how to utilize the current e-learning technologies, and identify a cost effective tool that can deliver the instructions [15].

This study aimed to evaluate the educational need, and the feasibility of implementation of a novel way of producing instructions that allow students to interact with content without the need for complex software programs or enormous amount of resources. Interactive textbook could be a new term that needs to be introduced to the health education literature. We would define it as a textbook in an electronic format that allows the learner to interact with its content through video, interactive diagrams, rotating $3 \mathrm{D}$ objects, multi-touch widgets, and animations.
The study design involved two hours of training on IBA application, and designing an I-textbook using this application. This approach for staff awareness, and training about CAL programs was one of tips to develop educational multimedia by Koller et al. [16]. The authors concluded that this approach reduce the anxiety level of using computer based teaching and promote the use of technology to deliver medical education as well as self-study via computer based teaching.

The target audience for the presentation was identified during study design. It consisted of a sampling of the people for whom the I-textbook is being created. The study limited the target audience to faculty members, as they will be working as I-textbooks creators, and students as end-users. Although the sample size was small (42 students, and 28 faculty members), but this was in agreement with Koller et al. [16], who recommended keeping the target audience to a manageable size.

The study showed that the faculty members were ready to use, and adopt the new application in preparing their instructions. The same finding was obtained by Hosny et al. [17] who introduced CAL materials in a clinical skill lab. The authors concluded that locally produced CAL materials might be better than just purchasing ready-made materials that may not suit the learning environment, and students' involvement in the process of production and evaluation of training materials is of considerable importance. This observation could be due to the simple, and easy use of the IBA as reported by faculty feedback "creating I-textbook using IBA is more or less similar to creating a presentation using PowerPoint, or Keynote".

The students reported the same positive feedback about using I-textbook. They said, "I-textbooks bring all knowledge in different forms together in one page, which motivated us to learn independently".

Pike stated that educators/trainers can do nothing to motivate learners but can create an environment where people will motivate themselves [18]. Accordingly, I-textbook can be regarded as a motivating environment for learning. This finding was also consistent with Mann principles to enhance learners' motivation. Mann suggested that making learning enjoyable and rewarding, and using teaching and learning strategies that are intrinsically motivating are two keys to enhance learners' motivation [19].

After the presentation, we found that more than $25 \%$ of faculty members were willing to shift to use Apple hardware, which is an indicator for their readiness to implement, and use I-textbook.

WHO reported a considerable strain on education systems in developing countries due to lack of resources [20]. IBA is a free application, which can be downloaded online, but this requires a hardware, which could range from USD 400 to USD 2000. The study showed that the educational institute is willing to provide the necessary hardware that enable I-textbooks creation. This vision could be different if there were a need to implement a complex program or an expensive virtual learning environment (VLE). Most e-learning resources have a high initial development cost and these results in a reluctance to share high quality and innovative content between institutions [21].

One of the roles of educational technologist is to resolve the tensions between what educators want and what is technically possible and desirable [5]. Now, IBA can help the medical teachers in developing their learning resources. Two of the twelve roles of medical teacher are defined under resource developer either for study guide, or for learning materials [22]. The role of the teacher as a resource developer will reduce such tensions, and the role of educational technologist will be limited to the creation of digital reusable learning objects that will be 
essential for feeding I-textbook. Using public domain graphic images could be another option to avoid copyright issues [16].

Limitation of the study: The study evaluated the reaction, and satisfaction of the participants, which is considered the first level of Kirkpatrick's hierarchy of evaluation. Therefore we recommend further studies to evaluate the new learning tool at the level of learning or knowledge gained, and the changes in health professionals' behaviours, and performance.

\section{Future Direction}

To the author's knowledge, this is the first research in dental education to evaluate the educational need, and the feasibility of implementation of I-textbooks. The future could show an increase in the production of digital reusable learning objects, with a gradual appearance of all printed textbook in an interactive format.

\section{Conclusion}

I-textbook designed by IBA is a motivating tool for students' learning, and can be easily implemented by the medical teacher in dental education.

\section{Conflict of Interest}

I declare "I have no dual commitment or any possible conflict of interest at the time of submission. These include financial interests".

\section{Ethical Approval}

I confirm that the Research Committee of my institute has approved this work and it is in agreement with the guidelines of the Helsinki Declaration as revised in 1975

\section{References}

1. Apple in education (2012)

2. Harden RM, Smyth JJ (1994) Computer-based study guides 11: educational components and advantages. Med Teach 16: 4-7.

3. Schittek M, Mattheos N, Lyon HC, Attström R (2001) Computer assisted learning. A review. Eur J Dent Educ 5: 93-100.

4. Mattheos N, Schittek MJ, Nattestad A, Shanley D, Attström R (2005) A comparative evaluation of computer literacy amongst dental educators and students. Eur J Dent Educ 9: 32-36.

5. Ellaway R, Masters K (2008) AMEE Guide 32: e-Learning in medical education Part 1: Learning, teaching and assessment. Med Teach 30: 455-473.
6. Kulik CC, Kulik JA (1991) Effectiveness of computer-based instruction: an updated analysis. Computers in Human Behavior 7: 75-94.

7. Rosenberg H, Grad HA, Matear DW (2003) The effectiveness of computer aided, self-instructional programs in dental education: a systematic review of the literature. J Dent Educ 67: 524-532.

8. Eitner S, Holst S, Wichmann M, Karl M, Nkenke E, et al. (2008) Comparative study on interactive computer-aided-learning and computer-aided-testing in patient-based dental training in maxillofacial surgery. Eur J Dent Educ 12: 35 40.

9. Vuchkova J, Maybury T, Farah CS (2012) Digital interactive learning of ora radiographic anatomy. Eur J Dent Educ 16: e79-87.

10. Mattheos N, Stefanovic N, Apse P, Attstrom R, Buchanan J, et al. (2008) Potential of information technology in dental education. Eur J Dent Educ 12 85-92.

11. Plasschaert AJ, Wilson NH, Cailleteau JG, Verdonschot EH (1995) Opinions and experiences of dental students and faculty concerning computer-assisted learning. J Dent Educ 59: 1034-1040.

12. Cross J, Shutt R (1998) Development of a computer-assisted educational resource. Med Teach 20: 592-594.

13. McGee JB, Kanter SL (2011) How we develop and sustain innovation in medical education technology: Keys to success. Med Teach 33: 279-285.

14. Norcini JJ, Banda SS (2011) Increasing the quality and capacity of education the challenge for the 21st century. Med Educ 45: 81-86.

15. Roberts DH, Newman LR, Schwartzstein RM (2012) Twelve tips for facilitating Millennials' learning. Med Teach 34: 274-278.

16. Koller CA, Frankenfield JJ, Sarley CA (2000) Twelve tips for developing educational multimedia in a community-based teaching hospital. Med Teach 22: 7-10.

17. Hosny S, Mishriky AM, Youssef M (2008) Introducing computer-assisted training sessions in the clinical skills lab at the Faculty of Medicine, Suez Canal University. Med Teach 30: e35-40.

18. Pike RW (2003) Creative Training Techniques Handbook: Tips, Tactics, and How-to's for Delivering Effective Training. Human Resource Development Press, Inc, USA: 30-50.

19. Mann KV (1999) Motivation in medical education: how theory can inform ou practice. Acad Med 74: 237-239.

20. WHO Consultative Meeting (2002) New Approaches in Oral Health Training and Education in Africa. Cape Town, South Africa: 1-6.

21. Sandars J (2009) E-learning in medical education: Guide supplement 32.1--viewpoint. Med Teach 31: 362-363.

22. Harden RM, Crosby J (2000) AMEE Guide No 20: The good teacher is more than a lecturer - the twelve roles of the teacher. Med Teach 22: 334-347. 